\title{
Evaluation of cardiotocographic and cord blood changes in induced labor with dinoprostone and misoprostol
}

\author{
Kiran Pandey ${ }^{1}$, Ajay Bhagoliwal ${ }^{2}$, Neetu Singh ${ }^{1}$, Sangeeta Arya ${ }^{1}$, \\ Yashwant Kumar Rao ${ }^{3}$, Shweta Mishra ${ }^{1}$
}

\footnotetext{
${ }^{1}$ Department of Obstetrics \& Gynecology, GSVM Medical College, Kanpur, Uttar Pradesh, India

${ }^{2}$ Professor Statistics, GSVM Medical College, Kanpur, Uttar Pradesh, India

${ }^{3}$ Department of Pediatrics, GSVM Medical College, Kanpur, Uttar Pradesh, India
}

Received: 13 February 2014

Accepted: 22 February 2014

\author{
*Correspondence: \\ Dr. Kiran Pandey, \\ E-mail: dr.kiranpandey@gmail.com
}

(C) 2014 Pandey K et al. This is an open-access article distributed under the terms of the Creative Commons Attribution Non-Commercial License, which permits unrestricted non-commercial use, distribution, and reproduction in any medium, provided the original work is properly cited.

\begin{abstract}
Background: To evaluate the cardiotocographic abnormalities associated with induction of labour with misoprostol and dinoprostone and comparing the perinatal outcome in terms of cord blood analysis.

Methods: This study was conducted in the department of Obstetrics and Gynecology of G.S.V.M. Medical College, Kanpur with 80 patients. Cases were randomly divided into two groups with $n=40$. In first group $50 \mu$ gm misoprostol per vaginally and in second group $0.5 \mathrm{mg}$ of dinoprostone gel was used for induction. Cardiotocography of all the study candidates was performed and following delivery cord blood gas analysis was done.

Results: It was found that $45 \%$ percent of women treated with misoprostol demonstrated an abnormal tracing event within the initial 24 hours of induction, compared with $17.5 \%$ in the dinoprostone gel. Both hypertonus and tachysystole events were significantly more frequent in women treated with misoprostol group and this difference is statistically significant $(\mathrm{p}=0.0099)$. We also found that these events occurred earlier after initial misoprostol dosing $(6.98 \pm 4.14 \mathrm{hr})$, compared with the dinoprostone gel $(9.19 \pm 6.29 \mathrm{hr})$.

Conclusions: Cardiotocographic abnormalities are more frequent after misoprostol administration compared with the dinoprostone gel. Neonatal outcome in terms of NICU admission and Umbilical artery cord blood changes are apparently similar in both.
\end{abstract}

Keywords: Induction, Cardiotocography, Misoprostol, Dinoprostone

\section{INTRODUCTION}

Induction of labour is a method of artificially or prematurely stimulating labour in women. When the risks of continuation of pregnancy either to the mother or to the fetus are more, induction is indicated. Transition from pregnancy to labour is a gradual process, called prelabour marked by increased uterine contractility and cervical ripening. The success of induction depends on the degree of these pre-labour changes. Bishop's score and fetal maturity is to be assessed prior to induction. If Bishop's score is less than 6 , it is recommended that a cervical ripening agent be used before labour induction.
Prostaglandins are highly efficacious cervical ripening agents that are useful clinically as an adjuvant to labour induction in patients with unfavourable cervix to shorten induction to delivery interval, improve induction success, and reduce morbidities associated with prolonged labour induction. The use of these agents, however, is associated with potential for uterine contraction and fetal heart tracing abnormalities. Cardiotocography is an electronic method of simultaneously recording fetal heart rate (FHR), fetal movements and uterine contraction to identity the probability of fetal compromise. Cord blood gas analysis monitors the arterial and venous cord blood for levels of oxygen and carbon dioxide while also testing 
the $\mathrm{pH}$. Essentially, the test tells whether the infant has been subjected to oxygen deprivation at birth.

\section{METHODS}

This study was conducted in the Department of Obstetrics and Gynecology of G.S.V.M. Medical College, Kanpur. A total of 80 patients were studied. A written informed consent was taken from those who volunteered to participate. All the cases were randomly divided into two groups each having $\mathrm{n}=40$. In first group $50 \mu \mathrm{gm}$ misoprostol per vaginally was used for induction of labour and in second group $0.5 \mathrm{mg}$ of dinoprostone gel was used for induction.

Main inclusion criteria were singleton pregnancy with vertex presentation and unfavourable cervical bishop score of 5 or less. There should be no spontaneous uterine contraction (i.e. $<4$ spontaneous contraction per hour) \& non stress test should be reactive. There should be no contraindication to vaginal delivery.

Main exclusion criteria were ruptured membranes \& suspected chorioamnionitis, parity more than five, previous caesarean delivery or history of uterine surgery and previous attempted induction of labour for this pregnancy.

Cardiotocography of all the study candidates was performed to rule out fetal distress and presence of uterine contractions. A cervical Bishop Score was assigned on admission to all patients in the study. Participants were then randomly assigned to preinduction cervical ripening with misoprostol $50 \mathrm{mcg}$ intravaginally in the posterior fornix initially and repeat dosing 6 hours later or dinoprostone gel $0.5 \mathrm{mg}$ administered intracervically initially with repeat dosing 6 hours later. Patients with established contractions pattern of greater than 3 contractions in 10 minutes were not redosed with study agents. After the preinduction interval, a repeat Bishop score was assigned to the patients. Patient not in an adequate labour pattern after the preinduction interval received standard oxytocin infusion, until an adequate contraction pattern was obtained. Electronic fetal heart rate and tocodynamic monitoring was done. Standardized intrapartum management guidelines were followed for all patients. Cardiotocographic tracings were reviewed and any abnormalities were coded using established definitions.

Immediately after delivery a segment of umbilical cord was double clamped and blood was taken from the artery using pre-heparinized syringe and sent to laboratory to determine $\mathrm{pH}$ and blood gas values.

\section{RESULTS}

Majority of patients in both misoprostol and dinoprostone groups were primigravida $(62 \%)$. A total of 50 patients were primigravida out of which 28 were in misoprostol group $(70 \%)$ and 22 were in dinoprostone group (55\%). Maximum numbers of patients in both the groups were in the age group 20-25 years. Mean age group in the misoprostol group was $24.575 \pm 2.44$ and in dinoprostone group was $24.90 \pm 2.34$.

$45 \%$ patients in Misoprostol group required only single dose while $60 \%$ cases in dinoprostone group required 2 doses. Average number of doses required in misoprostol and dinoprostone group is $1.95 \pm 0.7494$ and $1.70 \pm$ 0.5639 respectively. Mean induction delivery interval in Misoprostol group is $11.85 \pm 4.26 \mathrm{hr}$. Mean induction delivery interval in dinoprostone group is $12.75 \pm 4.22 \mathrm{hr}$. Incidence of caesarean section was $20 \%$ in misoprostol and $17.5 \%$ cases in dinoprostone group.

Table 1 shows that overall cardiotocographic abnormalities occurred in $45 \%$ cases of Misoprostol group and in $17.5 \%$ cases of dinoprostone group. In misoprostol group tachysystole occurred in 30\%, Hypertonus in $2.5 \%$ and hyperstimulation in $12.5 \%$ cases while in dinoprostone group $12.5 \%$ had tachysystole, $5 \%$ had hyperstimulation and none had hypertonus.

Table 1: Incidence of cardiotocographic abnormalities.

\begin{tabular}{|c|c|c|c|c|c|c|c|c|c|}
\hline \multicolumn{10}{|c|}{ Cardio-tocographic abnormality } \\
\hline \multirow{2}{*}{ Sr. No. } & \multirow{2}{*}{ Groups } & \multicolumn{2}{|c|}{ Tachysystole } & \multicolumn{2}{|c|}{ Hyper-tonus } & \multicolumn{2}{|c|}{ Hyper-stimulation } & \multicolumn{2}{|c|}{ Overall } \\
\hline & & No. & $\%$ & No. & $\%$ & No. & $\%$ & No. & $\%$ \\
\hline 1 & Misoprostol $(n=40)$ & 12 & 30 & 1 & 2.5 & 5 & 12.5 & 18 & 45 \\
\hline 2 & Dinoprostone $(n=40)$ & 5 & 12.5 & 0 & 0 & 2 & 5 & 7 & 17.5 \\
\hline
\end{tabular}

Table 2 shows that mean time of appearance of cardiotocographic abnormality in misoprostol group is $6.69 \pm 3.28 \mathrm{hr}$ and in dinoprostone group is $7.86 \pm 3 \mathrm{hr}$.
Table 3 shows that FHR $<110$ bpm (bradycardia) was seen in $5 \%$ cases with misoprostol and $2.5 \%$ cases with dinoprostone. FHR $>160 \mathrm{bpm}$ (tachycardia) was seen in $10 \%$ cases with misoprostol and $7.5 \%$ cases with 
dinoprostone. FHR variability was less than 5 in $10 \%$ cases of misoprostol group and $7.5 \%$ cases of dinoprostone group. No accelerations were present in $5 \%$ cases of both misoprostol and dinoprostone group. Decelerations were present in $22.5 \%$ cases of misoprostol and $17.5 \%$ cases of dinoprostone group.

Table 2: Time of appearance of cardiotocographic abnormalities.

\begin{tabular}{|c|c|c|c|c|c|c|c|c|}
\hline \multirow{3}{*}{ Sr. No. } & \multirow{3}{*}{ Groups } & \multicolumn{6}{|c|}{ Time for cardio-tocographic abnormality (hours) } & \multirow{3}{*}{ Mean \pm SD } \\
\hline & & \multicolumn{2}{|l|}{$<6$} & \multicolumn{2}{|c|}{ 6-12 } & \multicolumn{2}{|c|}{$>12$} & \\
\hline & & No. & $\%$ & No. & $\%$ & No. & $\%$ & \\
\hline 1 & Misoprostol $(\mathrm{n}=40)$ & 11 & 27.5 & 5 & 12.5 & 2 & 5 & $6.69 \pm 3.28$ \\
\hline 2 & Dinoprostone $(n=40)$ & 2 & 5 & 4 & 10 & 1 & 2.5 & $7.86 \pm 3.19$ \\
\hline
\end{tabular}

Table 3: Fetal heart rate patterns.

\begin{tabular}{|c|c|c|c|c|c|}
\hline \multirow[b]{2}{*}{ Sr. No. } & \multirow[b]{2}{*}{$\begin{array}{l}\text { Fetal } \\
\text { heart } \\
\text { rate } \\
\text { pattern }\end{array}$} & \multicolumn{2}{|c|}{$\begin{array}{l}\text { Misoprostol } \\
(n=40)\end{array}$} & \multicolumn{2}{|c|}{$\begin{array}{l}\text { Dinoprostone } \\
(n=40)\end{array}$} \\
\hline & & No. & $\%$ & No. & $\%$ \\
\hline & \multicolumn{5}{|c|}{ Baseline FHR } \\
\hline 1 & $<110$ & 2 & 5 & 1 & 2.5 \\
\hline 2 & $110-160$ & 34 & 85 & 36 & 90 \\
\hline 3 & $>160$ & 4 & 10 & 3 & 7.5 \\
\hline & \multicolumn{5}{|c|}{ Fetal heart rate variability } \\
\hline 1 & $<5$ & 4 & 10 & 3 & 7.5 \\
\hline 2 & $5-25$ & 36 & 90 & 37 & 92.5 \\
\hline 3 & $>25$ & 0 & 00 & 0 & 00 \\
\hline & \multicolumn{5}{|c|}{ Number of accelerations } \\
\hline 1 & 0 & 2 & 5 & 2 & 5 \\
\hline 2 & $1-2$ & 6 & 15 & 4 & 10 \\
\hline 3 & $>2$ & 32 & 80 & 34 & 85 \\
\hline & \multicolumn{5}{|c|}{ Decelerations } \\
\hline 1 & Early & 5 & 12.5 & 4 & 10 \\
\hline 2 & Late & 2 & 5 & 1 & 2.5 \\
\hline 3 & Variable & 2 & 5 & 2 & 5 \\
\hline
\end{tabular}

Table 4 shows that Baby's APGAR score at 1 and 5 min is an important parameter to assess the well-being of neonate after delivery. Mean APGAR score at $1 \mathrm{~min}$ in misoprostol group was $6.3 \pm 1.47$ and in dinoprostone group was $6.45 \pm 1.395$. Mean APGAR score at $5 \mathrm{~min}$ in misoprostol group was 8.575 \pm 0.8439 and in dinoprostone group it was $8.40 \pm 0.6718$. The perinatal outcome in form of NICU admissions was $20 \%$ misoprostol group and $15 \%$ in dinoprostone group.

Table 4: Neonatal outcome.

\begin{tabular}{|c|c|c|c|c|c|}
\hline \multirow[t]{2}{*}{ Sr. No. } & & \multicolumn{2}{|c|}{$\begin{array}{l}\text { Misoprostol } \\
(\mathrm{n}=40)\end{array}$} & \multicolumn{2}{|c|}{$\begin{array}{l}\text { Dinoprostone } \\
(n=40)\end{array}$} \\
\hline & & No. & $\%$ & No. & $\%$ \\
\hline & \multicolumn{5}{|c|}{ APGAR score at 1 min } \\
\hline 1 & $<3$ & 1 & 2.5 & 0 & 0 \\
\hline 2 & $3-8$ & 37 & 92.5 & 37 & 92.5 \\
\hline 3 & $>8$ & 2 & 5 & 3 & 7.5 \\
\hline \multicolumn{6}{|c|}{ APGAR score at 5 min } \\
\hline 1 & $<7$ & 1 & 2.5 & 0 & 0 \\
\hline 2 & $7-8$ & 17 & 42.5 & 24 & 60.0 \\
\hline 3 & $>8$ & 22 & 55.0 & 16 & 40.0 \\
\hline \multicolumn{6}{|c|}{ NICU admission } \\
\hline 1 & $\begin{array}{l}\text { Meconium } \\
\text { aspiration } \\
\text { syndrome }\end{array}$ & 3 & 7.5 & 2 & 5 \\
\hline 2 & $\begin{array}{l}\text { Hyperbilirub } \\
\text { inemia }\end{array}$ & 3 & 7.5 & 3 & 7.5 \\
\hline 3 & $\begin{array}{l}\text { Perinatal } \\
\text { asphyxia }\end{array}$ & 1 & 2.5 & 1 & 2.5 \\
\hline 4 & $\begin{array}{l}\text { Neonatal } \\
\text { sepsis }\end{array}$ & 1 & 2.5 & 0 & 0 \\
\hline
\end{tabular}

Table 5: Umbilical arterial blood gas analysis: Distribution of umbilical arterial blood gas and pH in neonates.

\begin{tabular}{|c|c|c|c|c|c|c|c|c|c|}
\hline \multirow{3}{*}{$\begin{array}{l}\text { Sr. } \\
\text { No. }\end{array}$} & \multirow{3}{*}{ Groups } & \multicolumn{8}{|l|}{ UA } \\
\hline & & PH & & $\mathrm{PCO}_{2}$ & & $\mathbf{P O}_{2}$ & & BE & \\
\hline & & Range & Mean \pm SD & Range & Mean \pm SD & Range & Mean \pm SD & Range & Mean \pm SD \\
\hline 1 & $\begin{array}{l}\text { Misoprostol } \\
(\mathrm{n}=40)\end{array}$ & $\begin{array}{l}7.07- \\
7.26\end{array}$ & $7.21 \pm 0.039$ & $\begin{array}{l}51.40- \\
62.8\end{array}$ & $56.07 \pm 2.53$ & $\begin{array}{l}12.6- \\
30.3\end{array}$ & $21.30 \pm 4.52$ & $\begin{array}{l}(-2)- \\
(-12)\end{array}$ & (-) $4.24 \pm 0.34$ \\
\hline 2 & $\begin{array}{l}\text { Dinoprostone } \\
(\mathrm{n}=40)\end{array}$ & $\begin{array}{l}7.0- \\
7.25\end{array}$ & $7.21 \pm 0.034$ & $50-65$ & $55.66 \pm 2.39$ & $\begin{array}{l}11.6- \\
28.5\end{array}$ & $19.70 \pm 4.185$ & $\begin{array}{l}(-3)- \\
(-11)\end{array}$ & (-) $4.24 \pm 0.34$ \\
\hline
\end{tabular}


Table 5 shows that mean umbilical arterial $\mathrm{pH}, \mathrm{PCO}_{2}$, $\mathrm{PO}_{2}$ and base excess in misoprostol group was $7.21 \pm$ $0.039 ; 56.07 \pm 2.53 ; 21.3 \pm 4.52$ and $4.24 \pm 34$ respectively and in dinoprostone group was $7.21 \pm 0.034$; $55.66 \pm 2.39 ; 19.7 \pm 4.185$ and $4.24 \pm 34$ respectively.

\section{DISCUSSION}

$45 \%$ percent of women treated with misoprostol demonstrated an abnormal tracing event within the initial 24 hours of induction, compared with $17.5 \%$ in the dinoprostone gel. Both hypertonus and tachysystole events were significantly more frequent in women treated with misoprostol compared with either the dinoprostone gel. Logistic regression analysis was applied to assess this difference. Result showed that Regression coefficient is statistically significant $(p=0.0099)$ which can be interpreted clinically as occurrence of cardiotocographic abnormalities is more in misoprostol group and this difference is statistically significant. The odds ratio is 0.2593 which implies that the probability of cardiotocographic abnormality is 0.2593 times less in dinoprostone group. We can also say that it is 3.8 times more in misoprostol group. In addition we have found that these events occurred earlier after initial misoprostol dosing $(6.98 \pm 4.14 \mathrm{hr})$, compared with the dinoprostone gel $(9.19 \pm 6.29 \mathrm{hr})$. For analysing this difference independent sample ' $t$ ' test has been used and value of ' $t$ ' came out to be $1.37, p=0.1795$ which implies that this difference is statistically not significant and may be due to chance as well. Frohn WE et al. (2002) ${ }^{1}$ reported that Tachysystole occurred in $20 \%$ and $6 \%$ of women in misoprostol and $\mathrm{PGE}_{2}$ respectively. Hyper stimulation occurred in $9 \%$ and $6 \%$. They concluded that intravaginal misoprostol is more effective than local $\mathrm{PGE}_{2}$ application to treat PROM after 34 weeks of gestation but tachysystole occurs more commonly with misoprostol. Gregson S et al. $(2005)^{2}$ however reported that the incidence of uterine contraction abnormalities (tachysystole and hyperstimulation) and the incidence of abnormal CTG recordings were similar for both groups. Ramsey P. S. et al. $(2005)^{3}$ also reported that cardiotocographic abnormalities are more frequent after misoprostol administration compared with dinoprostone analogue. In their study 55\% women treated with misoprostol demonstrated an abnormal tracing event within initial 24 hours of induction, compared to $31.4 \%$ with dinoprostone gel. In addition these events occurred earlier after misoprostol dosing (1.6 \pm 5.6 hours $)$ compared to dinoprostone gel $(7.7 \pm 6.6$ hours $)$.

FHR $<110$ bpm (bradycardia) was seen in 5\% cases with misoprostol and $2.5 \%$ cases with dinoprostone. FHR $>160$ bpm (tachycardia) was seen in $10 \%$ cases with misoprostol and $7.5 \%$ cases with dinoprostone and this difference is statistically insignificant $(\mathrm{p}=0.375)$ FHR variability was less than 5 in $10 \%$ cases of misoprostol group and $7.5 \%$ cases of dinoprostone group and this difference is statistically insignificant $(p=0.623)$. No accelerations were present in $5 \%$ cases of both misoprostol and dinoprostone group. Decelerations were present in $22.5 \%$ cases of misoprostol and $17.5 \%$ cases of dinoprostone group. Logistic regression analysis was applied to assess this difference which showed that occurrence of decelerations in misoprostol and dinoprostone group is statistically not significant $(p=0.577)$. Langenegger EJ et al. $(2005)^{4}$ found that there were no significant differences in respect of the number of vaginal deliveries within $24 \mathrm{~h}$ (RR 1.12 ; $95 \%$ CI 0.88 1.42) between misoprostol and dinoprostone group. The frequency of suspicious and pathological fetal heart rate patterns did not differ significantly.

Baby's APGAR score at 1 and $5 \mathrm{~min}$ is an important parameter to assess the well-being of neonate after delivery. Mean APGAR score at $1 \mathrm{~min}$ in misoprostol group was $6.3 \pm 1.47$ and in dinoprostone group was 6.45 \pm 1.395 . Independent ' $t$ ' test was applied to analyse the difference between APGAR score and it was found to be statistically not significant $(\mathrm{t}=0.468$ and $\mathrm{p}=0.6411)$. Mean APGAR score at $5 \mathrm{~min}$ in misoprostol group was $8.575 \pm 0.8439$ and in dinoprostone group it was $8.40 \pm$ 0.6718. Independent ' $t$ ' test was applied to assess this difference and it was found to be statistically not significant $(t=1.026$ and $p=0.308)$. Similar results were obtained by Wang $\mathrm{Z}$ et al. (1997) ${ }^{5}$ and Papanikolaou et al. (2004). The perinatal outcome in form of NICU admissions was $20 \%$ misoprostol group and $15 \%$ in dinoprostone group. Ozkan S et al. (2009) ${ }^{6}$ also observed that mode of delivery, rate of cesarean sections due to fetal distress and adverse neonatal outcome were not demonstrated to be significantly different between misoprostol and dinoprostone groups $(\mathrm{P}=1, \mathrm{P}=0.5, \mathrm{P}=$ $0.4, \mathrm{P}=0.22, \mathrm{P}=0.5$ )

Mean umbilical arterial $\mathrm{pH}, \mathrm{PCO}_{2}, \mathrm{PO}_{2}$ and base excess in misoprostol group was $7.21 \pm 0.039 ; 56.07 \pm 2.53$; $21.3 \pm 4.52$ and $4.24 \pm 0.34$ respectively and in dinoprostone group was $7.21 \pm 0.034 ; 55.66 \pm 2.39 ; 19.7$ \pm 4.185 and $4.24 \pm 0.34$ respectively. Independent $t$ test was applied and it was found to be statistically not significant (For $\mathrm{pH} \mathrm{t}=0.425$ and $\mathrm{p}=0.672 ; \mathrm{PCO}_{2} \mathrm{t}=$ 1.647 and $\mathrm{p}=0.103 ; \mathrm{PO}_{2} \mathrm{t}=0.757$ and $\mathrm{p}=0.451$ and base excess $t=0.099$ and $p=0.921)$. Similar results were reported by Mundle W. R. et al. (1996). ${ }^{7}$ They found that mean $( \pm \mathrm{SD})$ time to vaginal delivery was $753 \pm 588$ minutes for misoprostol versus $941 \pm 506$ minutes for the physician chosen combination $(\mathrm{P}=0.018)$. There was no significant difference in caesarean rate or maternal morbidity. Neonatal outcomes, including cord blood acid base analysis were not significantly different.

\section{CONCLUSIONS}

Thus we can conclude from our study that both misoprostol and dinoprostone are effective drugs for induction of labour with no significant difference in induction delivery interval, oxytocin requirement and mode of delivery. Neonatal outcome in terms of cord blood gas analysis, APGAR score at 1 and 5 minutes, 
NICU admission are apparently similar in both. However cardiotocographic abnormalities are more frequent after misoprostol administration compared with the dinoprostone gel so misoprostol should be cautiously used with continuous fetal heart rate and tocodynamic monitoring.

\section{ACKNOWLEDGEMENTS}

The contribution of every author was appreciable along with the institution where study was conducted and all authors extend their sincere thanks to the patient who gave their consent for the inclusion in the study.

\section{Funding: No funding sources}

Conflict of interest: None declared

Ethical approval: The study was approved by the institutional ethics committee

\section{REFERENCES}

1. Frohn WE, Simmon S, Carlan SJ. Prostaglandin E2 gel versus misoprostol for cervical ripening in patients with premature rupture of membranes after 34 weeks. Obstet Gynaecol. 2002 Feb;99(2):206-10.

2. Gregson S, Waterstone M, Norman I, Murrells T. A randomised controlled trial comparing low dose vaginal misoprostol and dinoprostone vaginal gel for inducing labour at term. Br J Obstet Gynaecol. 2005 Apr;112(4):438-44.

3. Ramsey P. S., Meyer L, Walker B. A., Harris D, Oqburn P. L. Jr, Heise R. H., Ramin K. D. Cardiotocographic abnormalities associated with dinoprostone and misoprostol cervical ripening. Obstet Gynecol. 2005 Jan;105(1):85-90.

4. Langenegger EJ, Odendaal HJ, Grové D. Oral misoprostol versus intracervical dinoprostone for induction of labor. Int J Gynaecol Obstet. 2005 Mar;88(3):242-8.

5. Ozkan S, Caliskan E, Doger E, Yiicesoy I, Ozeren S, Vural B. Comparative efficacy and safety of vaginal misoprostol versus dinoprostone vaginal insert in labour induction at term: a randomized clinical trial. Arch Gynecol Obstet. 2009 Jul;280(1):19-24.

6. Wang Z, Li W, Ouyang W. Safety and efficacy of intravaginal misoprostol for cervical ripening in the third trimester of pregnancy. Zhonghua Fu Chan Ke Za Zhi. 1997 Jun;32(6):326-8.

7. Mundle MR, Young DC. Vaginal misoprostol for induction of labour. A randomized controlled trial. Obstet Gynecol. 1996 Oct;88(4):521-5.

DOI: $10.5455 / 2320-1770 . i j r \operatorname{cog} 20140340$

Cite this article as: Pandey K, Bhagoliwal A, Singh N, Arya S, Rao YK, Mishra S. Evaluation of cardiotocographic and cord blood changes in induced labor with dinoprostone and misoprostol. Int J Reprod Contracept Obstet Gynecol 2014;3:199-203. 